\title{
Carcinostatic effects of diverse ascorbate derivatives in comparison with aliphatic chain moiety structures: Promotion by combined hyperthermia and reduced cytotoxicity to normal cells
}

\author{
RYOKO ASADA $^{1}$, KATSUHIRO KAGEYAMA ${ }^{1}$, HIROSHI TANAKA ${ }^{2}$, MASATUGU KIMURA ${ }^{3}$, \\ YASUKAZU SAITOH ${ }^{4}$ and NOBUHIKO MIWA ${ }^{2,4}$ \\ ${ }^{1}$ Osaka Butsuryo College, Sakai, Osaka 593-8328; ${ }^{2}$ Faculty of Health Sciences, Butsuryo College of Osaka, Sakai, \\ Osaka 593-8324; ${ }^{3}$ Radioisotope Center, Osaka City University, Abeno-Ku, Osaka 545-8585; ${ }^{4}$ Faculty of Life \\ and Environmental Sciences, Prefectural University of Hiroshima, Shobara, Hiroshima 727-0023, Japan
}

Received December 9, 2011; Accepted January 30, 2012

DOI: $10.3892 / \mathrm{ol} .2012 .615$

\begin{abstract}
In this study, using human tongue squamous carcinoma cells (HSC-4) carcinostatic activity was compared for diverse $L$-ascorbic acid (Asc) derivatives, including the 'straight- $\mathrm{C}_{16}$-chain types',6- $O$-palmitoyl-Asc (A6-P) and Asc-2phosphate-6- $O$-palmitate sodium salt (APPS), as well as the 'branched-C $\mathrm{C}_{16}$-chain types', Asc-2-phosphate-6-O-(2'-hexyl) decanoate (APHD), an isomer of APPS, and Asc-2,3,5,6-O-tetra-(2'-hexyl)decanoate (VCIP). The order of magnitude of the carcinostatic effects at $37^{\circ} \mathrm{C}$ was: APPS $>$ A6-P $=\mathrm{APHD}>\mathrm{VCIP}$ and at $42^{\circ} \mathrm{C}$ was APPS $=\mathrm{A} 6-\mathrm{P}>\mathrm{APHD}>\mathrm{VCIP}$. Therefore, the two straight $\mathrm{C}_{16}$-chain derivatives, APPS and A6-P, had a greater effect compared to the two branched$\mathrm{C}_{16}$-chain Asc derivatives, which are considered to have more difficulty with 'orientation along cell-membrane-glycerolipid direction'. APPS-treated HCS-4 cells were observed for a decrease in cell number, cell shrinkage, pycnosis indicative of apoptosis and cell deformation. The order of cytotoxicity for the normal human dermal fibroblasts (OUMS-36) at $37^{\circ} \mathrm{C}$ was: A6-P (50\% inhibitory concentration: 150-300 $\mu \mathrm{M}$ ) >APHD $(450-600 \mu \mathrm{M})>>$ Asc $=$ APPS $(800-1000 \mu \mathrm{M})$. Accordingly, APHD was more cytotoxic than APPS, since the straight- $\mathrm{C}_{16}$-chain type, which was eliminated after the enzymatic esterolysis of APPS, is metabolized via the 'fatty acid $\beta$-oxidation cycle' more efficiently in normal cells. Thus, APPS had a greater advantage over APHD, A6-P and VCIP in terms of carcinostatic effects at $37^{\circ} \mathrm{C}$, carcinostasis promotion at $42^{\circ} \mathrm{C}$ and a decrease of cytotoxicity to normal cells. This observation suggests a marked potential for aliphatic chain-moiety
\end{abstract}

Correspondence to: Dr Nobuhiko Miwa, Faculty of Health Sciences, Butsuryo College of Osaka, Sakai, Osaka 593-8324, Japan E-mail: miwa@butsuryo.ac.jp

Key words: ascorbic acid derivative, carcinostatic effect, hyperthermia, human tongue squamous carcinoma HSC-4 cells structures as anticancer agents, due to their cancer-selective carcinostasis and combined efficacy with hyperthermia, without causing side effects.

\section{Introduction}

Ascorbic acid (Asc) and its oxidized form, dehydroascorbic acid, are important in the inhibitory control of the division and growth of cells in animal tissues (1). Asc has been reported to be a potent antitumor agent (2), but extremely high doses are required for carcinostatic effects. To increase the activity, Asc in combination with supplements $(3,4)$ and the use of its derivatives generate hydrogen peroxide $(5,6)$. Asc acylated with palmitic acid on the 6-O-site suppresses cell growth (7) and DNA synthesis (8). The 6-O-palmitoyl derivative of Asc has been demonstrated to exert cytotoxicity to tumor cells through hydrogen peroxide generation (6). The carcinostatic activity of diverse Asc derivatives consisting of a palmitoyl moiety and phosphatidyl moiety has been demonstrated. Their chemical structures are shown in Table I. In this study, their activity was compared using human tongue squamous carcinoma cells (HSC-4). Hyperthermia, is a potent cancer treatment (9), which inhibits the growth of tumor cells (10-12) and DNA synthesis (13-15), and is in clinical use for cancer therapy. This study aimed to examine whether these derivatives of Asc increase tumor cell death caused by hyperthermia, to further improve cancer treatment.

Tumor cells treated with Asc derivatives at $37^{\circ} \mathrm{C}$ or $42^{\circ} \mathrm{C}$ were examined. Firstly, differences in the carcinostatic ability between two types of Asc derivatives, the straight-chain types with palmitoyl moiety, Asc-2-phosphate-6- $O$-palmitate sodium salt (APPS) and 6-O-palmitoyl-Asc (A6-P), as well as the branched-chain types, Asc-2-phosphate-6-O-(2'-hexyl) decanoate (APHD) and Asc-2,3,5,6-O-tetra-(2'-hexyl) decanoate (VCIP), were examined. Then, differences in the carcinostatic ability between the isomers, APPS and APHD were assessed. Following that tumor cells administered with APPS and APHD were observed for morphological changes. 
Table I Diverse Asc derivatives examined and their chemical structures.

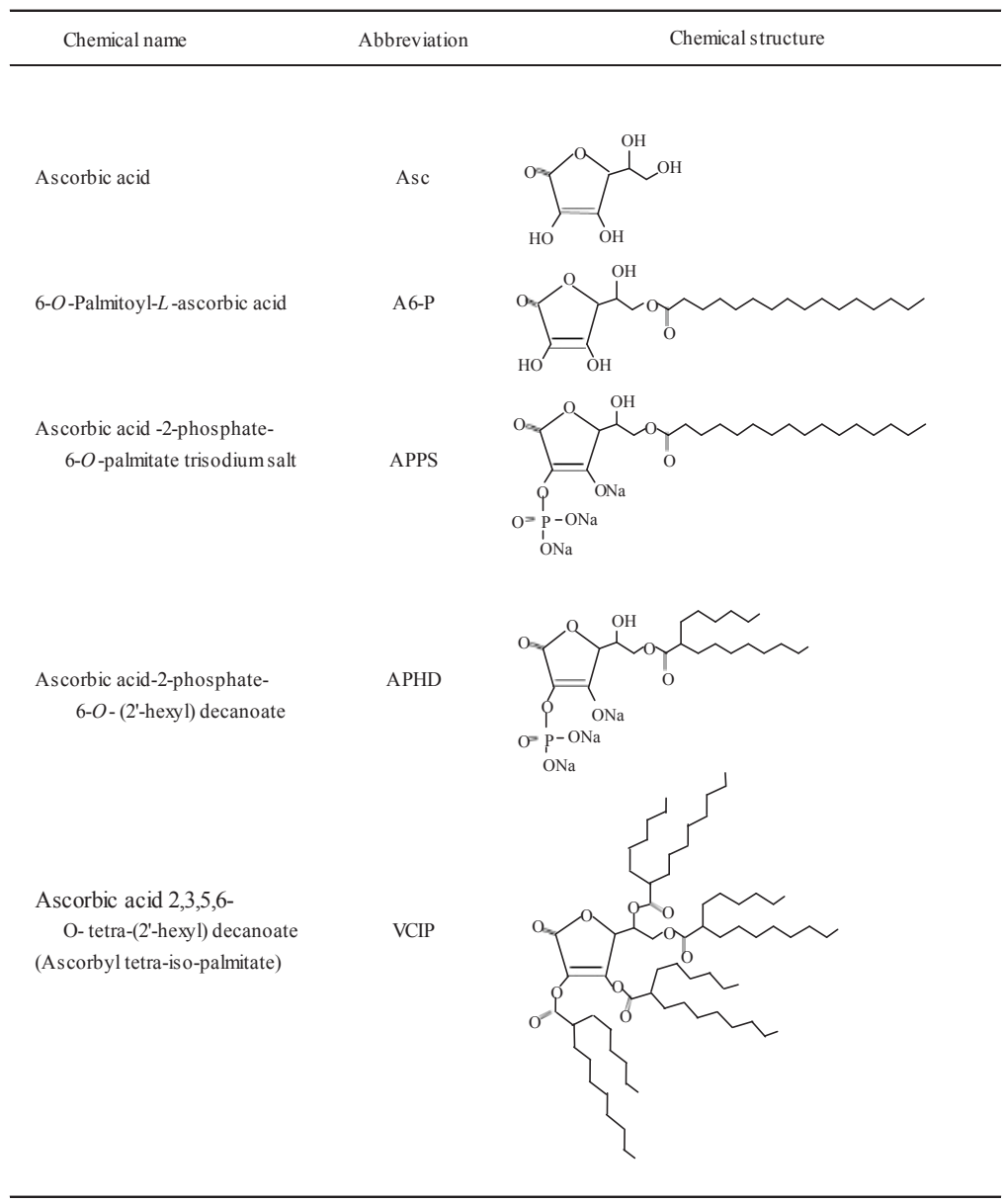

Finally, the side-effects of the Asc derivatives towards the normal (OUMS-36) cells were examined.

\section{Materials and methods}

Cell culture. Human tongue squamous carcinoma (HSC-4) cells were cultivated in Eagle's minimum essential medium (MEM; Nissui Pharmaceutical Co., Ltd., Tokyo) supplemented with $18 \%$ fetal bovine serum (FBS; Biological Industries Ltd., Israel) in a humidified atmosphere of $5 \% \mathrm{CO}_{2}$ in air at $37^{\circ} \mathrm{C}$.

Examination of carcinostatic effects. The examination of carcinostatic effects was conducted as previously described $(15,16)$. Cells were previously cultured for $24 \mathrm{~h}$ and suspended in culture medium at a density of $2 \times 10^{4}$ cells $/ \mathrm{ml}$. The test solutions of the diverse Asc derivatives were placed into test tubes. After the solvents were evaporated by jet flow of nitrogen gas, culture medium was added to the residue and sonicated to become homogenously emulsified. The cell suspensions and the test substance were mixed in a glass sample bottle (14 mm i.d. x $40 \mathrm{~mm}$ ). The cells were adjusted and diluted to a cell density of $2 \times 10^{4}$ cells $/ \mathrm{ml}$ and then, the bottle was tightly covered with a plastic cap.

Hyperthermic treatment. The suspension was incubated for $60 \mathrm{~min}$ at $37^{\circ} \mathrm{C}$ or $42^{\circ} \mathrm{C}$ in a water bath $(16,17)$ (BT-23 model,
Yamato Scientific Co., Ltd., Tokyo) and maintained by sequential culture in a humidified atmosphere of $5 \% \mathrm{CO}_{2}$ in air at $37^{\circ} \mathrm{C}$ for $24 \mathrm{~h}$

Cell viability assay. Cell viability was measured using the redox indicator dye WST-8 $(16,18)$ (Cell Counting kit, Dojin Chemicals, Kumamoto, Japan). The assay solution became increasingly chromic according to the mitochondrial dehydrogenase activity. The cultured cell suspension was transferred into a sampling tube and centrifuged. After the supernatant was completely removed from the tube, $110 \mu 18 \%$ WST- 8 was added to the cell precipitate, suspended and transferred into each well of a 96-well microplate. Following $3 \mathrm{~h}$ of incubation at $37^{\circ} \mathrm{C}$, the resulting Diformazan solution was determined by measuring the absorption at $450 \mathrm{~nm}$ using a plate reader (Benchmark, Bio-Rad Laboratories, Hercules, CA, USA).

Crystal violet staining. The carcinostatic activities were evaluated using a crystal violet stain assay followed by cell morphological observation $(18,19)$. The cell suspensions and the test tube substance were mixed in a 24-well culture plate (Becton, Dickinson and Co., Franklin Lakes, NJ, USA). The stain was then removed and the wells were rinsed thoroughly with running water until no additional dye leached from the wells. Cell morphology was observed under a phase-contrast microscope (Olympus IX-70). 
Statistical analysis. Student's t-test was used for statistical analysis, with $\mathrm{p}$ (probability) values $<0.05$ considered as indicative of statistical significance.

\section{Results}

Carcinostatic effects of diverse Asc derivatives and hyperthermia. The Asc derivatives were added to the HSC-4 cells. The culture samples were then heated in a water bath for $60 \mathrm{~min}$ at $37^{\circ} \mathrm{C}$ or $42^{\circ} \mathrm{C}$, and were maintained by sequential culture for $24 \mathrm{~h}$ at $37^{\circ} \mathrm{C}$. The carcinostatic effects were measured using a redox reaction-based WST-8 assay (Fig. 1). The cell viability of the control at $37^{\circ} \mathrm{C}$ was considered to be $100 \%$. At $37^{\circ} \mathrm{C}$, A6-P, APPS, APHD and VCIP yielded cell survival rates of $86.8 \pm 5.7,63.0 \pm 5.5(\mathrm{P}<0.0001), 88.01 \pm 3.70$ and $77.8 \pm 2.55 \%$, respectively. The cell viability for the control was reduced to $57.3 \pm 2.7 \%$ at $42^{\circ} \mathrm{C}(\mathrm{P}<0.0001)$. At $42^{\circ} \mathrm{C}$, A6-P, APPS, APHD and VCIP decreased cell viability to $42.0 \pm 2.1(\mathrm{P}<0.0001)$, $40.3 \pm 2.1(\mathrm{P}<0.0001), 60.6 \pm 4.3$ and $66.8 \pm 7.4 \%$, respectively. The carcinostatic activities of A6-P and APPS were markedly increased with hyperthermia.

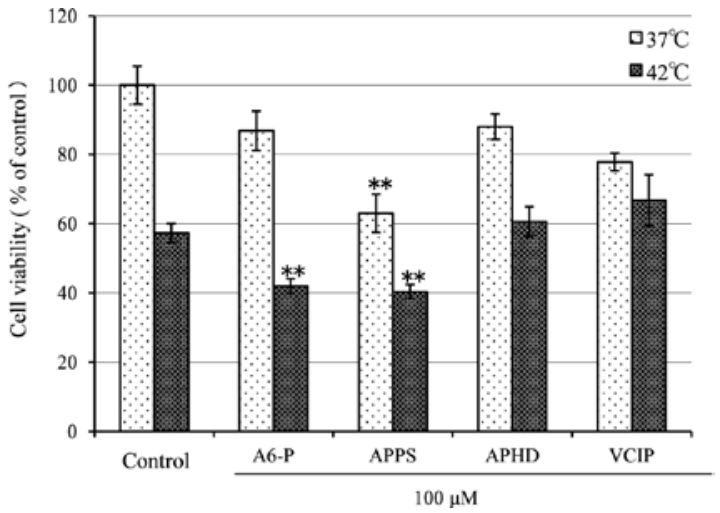

Figure 1. Carcinostatic effects of diverse Asc derivatives and hyperthermia on human tongue carcinoma cells (HSC-4) cultured for $24 \mathrm{~h}$ after heat treatment and evaluation by WST- 8 assay. Cells were seeded and cell viability was measured as indicated in Materials and methods. The absorbance of cells treated for $24 \mathrm{~h}$ in the absence of diverse Asc derivative at $37^{\circ} \mathrm{C}$ was $0.791 \pm 0.035$ or $0.715 \pm 0.027$ (the control value), respectively. Data shown represents the means \pm SD for quadruplicate measurements as percentages of the control value. ${ }^{* *} \mathrm{p}<0.001$ (vs.control). Asc, ascorbic acid; A6-P, 6- $O$-palmitoyl-Asc; APPS, Asc-2-phosphate-6- $O$-palmitate sodium salt; APHD, Asc-2-phosphate-6-O-(2'-hexyl)decanoate.

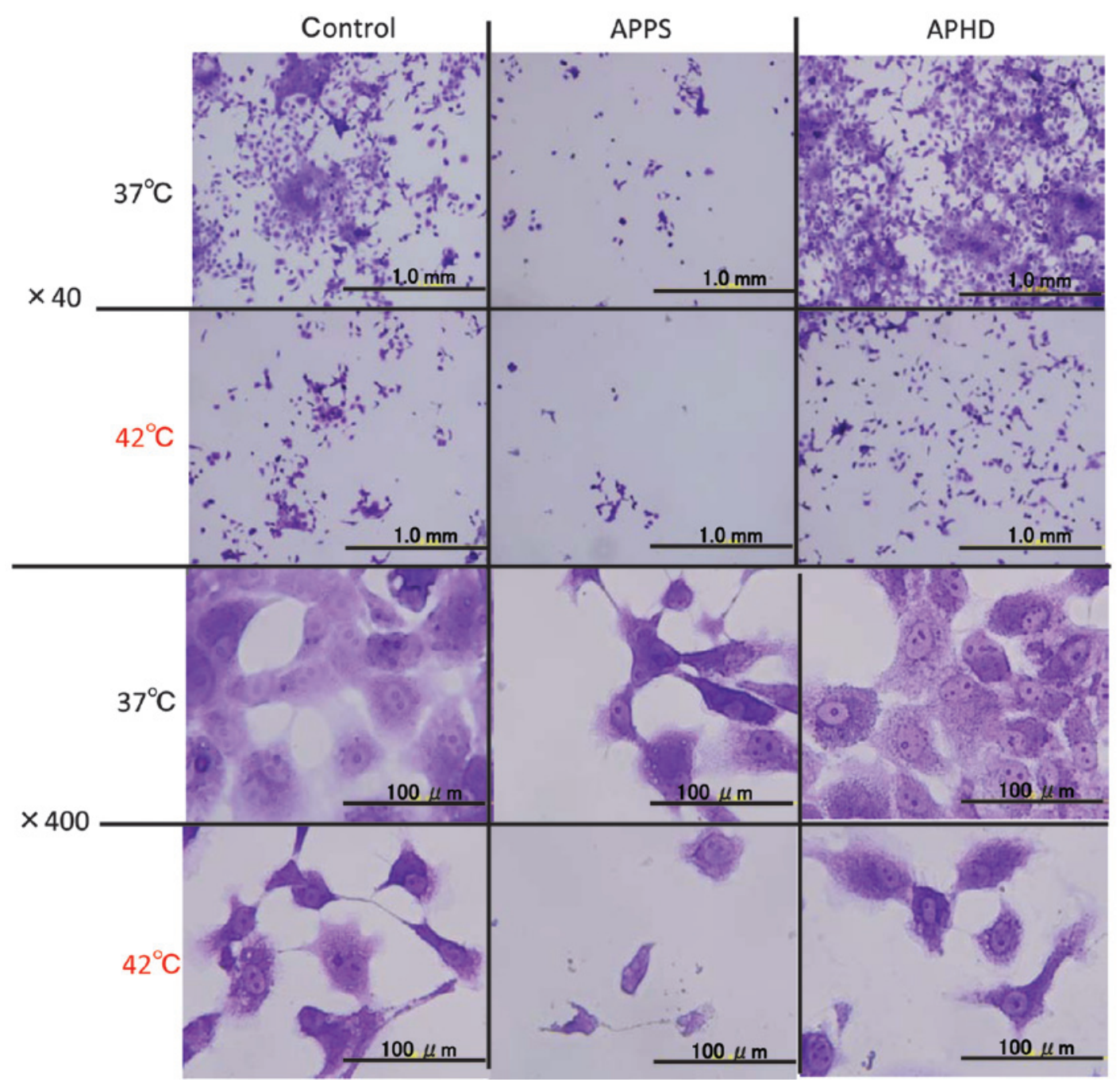

Figure 2. Morphological changes in HSC-4 cells treated with the control, APPS and APHD at body temperature and in combination with hypothermia using crystal violet stain assay. The cells were cultured for $24 \mathrm{~h}$ after the treatment at $37^{\circ} \mathrm{C}$ or $42^{\circ} \mathrm{C}$, stained with the crystal violet and photographed under the microscope. APPS, Asc-2-phosphate-6- $O$-palmitate sodium salt; APHD, Asc-2-phosphate-6- $O$-(2'-hexyl)decanoate. 


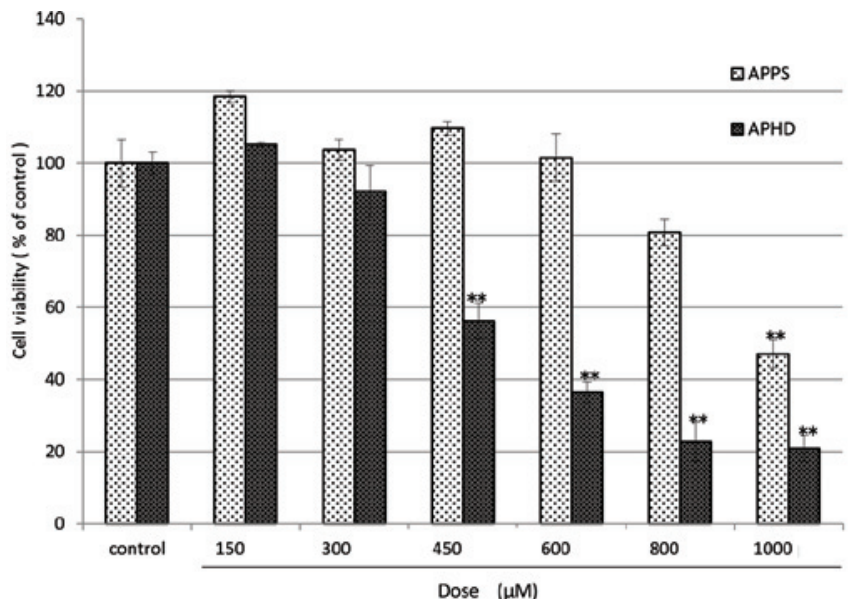

Figure 3. Cytotoxicities of APPS or APHD on normal human dermal fibroblast (OUMS-36) cells cultured for $24 \mathrm{~h}$. APPS or APHD was added to OUMS-36 cells. The culture samples were maintained by sequential culture for $24 \mathrm{~h}$ at $37^{\circ} \mathrm{C}$. Cell viability was measured by the absorption at $450 \mathrm{~nm}$ in the WST-8 assay. Data shown are the means \pm SD for quadruplicate measurements as percentages of the control value, ${ }^{* * *} \mathrm{p}<0.001$ (vs. control). APPS, Asc-2-phosphate-6- $O$-palmitate sodium salt; APHD, Asc2-phosphate-6-O-(2'-hexyl)decanoate.

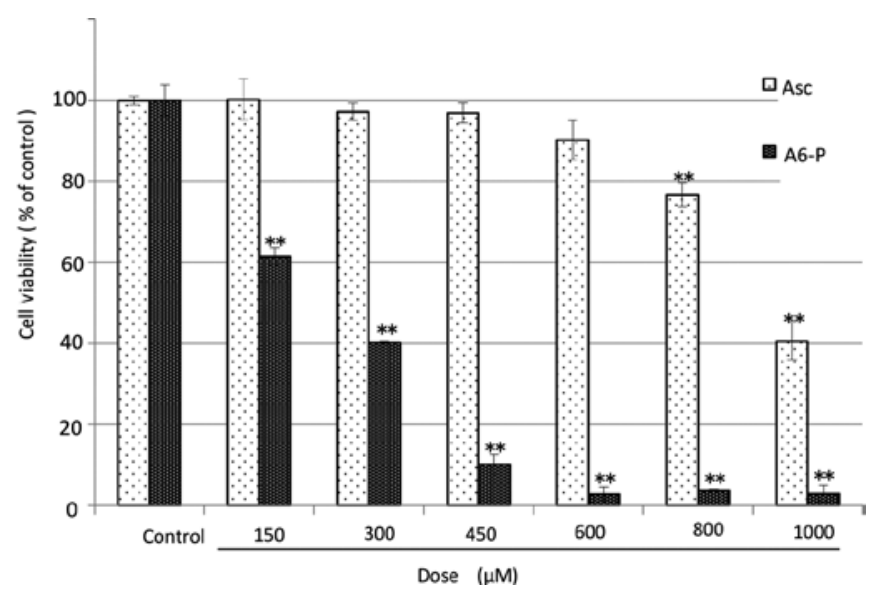

Figure 4. Cytotoxicities of Asc or A6-P on normal human dermal fibroblast (OUMS-36) cells cultured for $24 \mathrm{~h}$. Asc or A6-P was added to OUMS-36 cells. The culture samples were maintained by sequential culture for $24 \mathrm{~h}$ at $37^{\circ} \mathrm{C}$. Cell viability was measured by the absorption at $450 \mathrm{~nm}$ in the WST- 8 assay. Data shown are the means \pm SD for quadruplicate measurements as percentages of the control value, ${ }^{* *} \mathrm{p}<0.001$ (vs. control). Asc, ascorbic acid; A6-P, 6-O-palmitoyl-Asc.

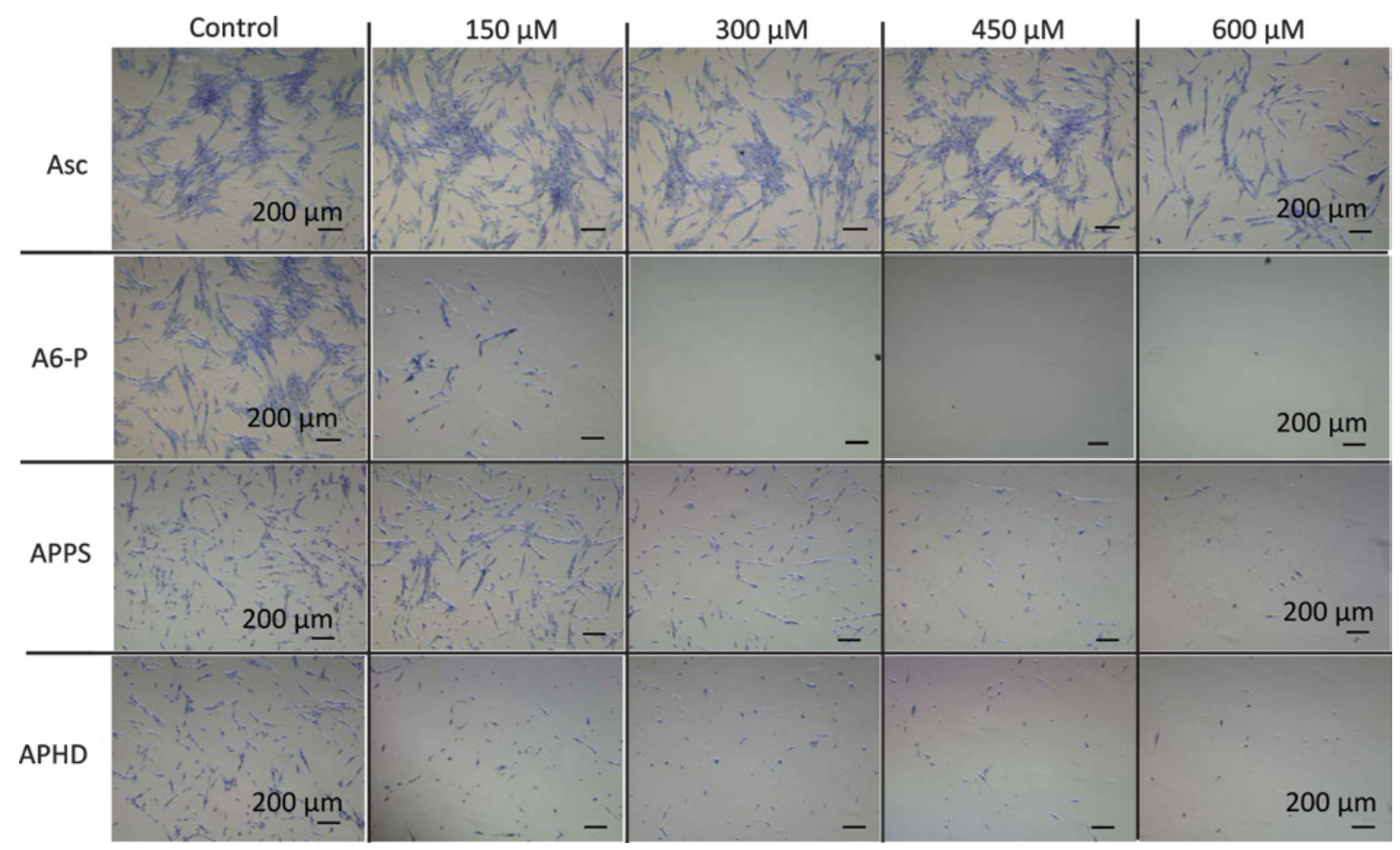

Figure 5. Morphological changes in tumor cells of Asc derivatives in OUMS-36 cells observed by crystal violet stain assay under the microscope. Asc, ascorbic acid; A6-P, 6- $O$-palmitoyl-Asc; APPS, Asc-2-phosphate-6- $O$-palmitate sodium salt; APHD, Asc-2-phosphate-6- $O$-(2'-hexyl)decanoate.

Morphological changes in tumor cells observed by crystal violet stain assay. Morphological observations in the tumor cells was performed by crystal violet staining, while the carcinostatic effects were assayed. The morphological changes occurred in the HSC-4 cells treated with APPS or APHD, which exhibited the greatest carcinostatic activities (Fig. 2). The morphological observations in the HCS-4 cells treated with APPS, were decreased cell numbers, cell shrinkage and pycnosis (nuclear condensation) indicative of apoptosis and cell deformation. At $42^{\circ} \mathrm{C}$, the morphological changes of the cells were increased and fragmentation of the cells was also observed.

Cytotoxicities of diverse Asc derivatives on OUMS-36 cells. The diverse Asc derivatives were added to OUMS-36 cells and the culture samples were maintained by sequential culture for 
$24 \mathrm{~h}$ at $37^{\circ} \mathrm{C}$. The cytotoxicities were measured by a WST- 8 assay (Figs. 3 and 4). The cell viability of the controls in the absence of the Asc derivative was considered to be $100 \%$. The order of magnitude of cytotoxicity at a dose of $600 \mu \mathrm{M}$ was as follows: A6-P>APHD>Asc $>$ APPS. APPS did not injure the OUMS-36 cells, even at $600 \mu \mathrm{M}$ (Fig. 3). This tendency was also exhibited in the morphological observation (Fig. 5)

\section{Discussion}

Among the studied diverse ascorbic acid (Asc) derivatives, the straight chain type palmitic acid-phosphorus acid derivative, APPS, demonstrated the greatest antitumor effect, whereas, the branched chain type, APHD, did not demonstrate any antitumor effects. This finding may be due to the fact that the straight chain type is considered to be more permeable through the cell membrane than the branched type. Asc radicals, which are produced by the enzyme-catalyzed esterolysis of APPS, are absorbed into the cells where they injure DNA leading to cell death. By contrast, the branched types, APHD and VCIP, are less permeable or not permeable through the cell membranes, and therefore not effective for carcinostasis. From the morphological observations of the HCS-4 cells treated with APPS, a decrease in cell number, cell shrinkage and pycnosis (nuclear condensation) indicative of apoptosis and cell deformation were observed. These observed morphological changes were increased upon combination with hyperthermia treatment where further fragmentation of the cells was also observed. Whether the Asc derivatives were cytotoxic to the normal cells was then examined. A6-P was found to be cytotoxic to the tumor cells and normal (OUMS-36) cells, APHD was cytotoxic to the normal cells, but scarcely to the tumor cells, and APPS was cytotoxic to the tumor cells but not the normal cells at a dose of $600 \mu \mathrm{M}$. The results demonstrate that APPS has a marked carcinostatic advantage over A6-P. This benefit may be due to the addition of the of 2-O-phosphatidyl moiety, which adjusts the molecular LHB (lipophilicity-hydrophilicity balance) to be more hydrophilic. By contrast, the branched chain type APHD, an isomer of APPS, was almost ineffective, even at $100 \mu \mathrm{M}$. This finding may be due to the difference in molecular structure, which is related to surface activity and cell membrane permeability.

In conclusion, APPS exhibited a marked carcinostatic effect, and therefore may be developed as a potent antitumor agent with limited side-effects towards normal cells, and as a promoter by combination with hyperthermia. APPS has also been demonstrated to inhibit invasion of human fibrosarcoma cells (HT-1080) through the constituted basement membrane Matrigel and metastasis of mouse melanoma cells (B16-BL6) transplanted from the tail vein in mice (20).

\section{Acknowledgements}

The authors thank Dr Shinya Kato for his technical assistance.
3. Poydock ME, Reikert D and Rice J: Influence of vitamins $C$ and $\mathrm{B} 12$ on the survival rate of mice bearing ascites tumor. Exp Cell Biol 50: 88-91, 1982.

4. Pierson HF, Fisher JM and Rabinovitz M: Depletion of extracellular cysteine with hydroxocobalamin and ascorbate in experimental murine cancer chemotherapy. Cancer Res 45: 4727-4731, 1985.

5. Hacker MP, Khokhar AR, Brown DB, McCormack JJ and Krakoff IH: Ascorbato(1,2-diaminocyclohexane): platinum (II) complexes, a new series of water-soluble antitumor drugs. Cancer Res 45: 4748-4753, 1985

6. Miwa N, Yamazaki H, Nagaoka Y, Kageyama K, Onoyama Y, Matsui-Yuasa I, Otani S and Morisawa S: Altered production of the active oxygen species is involved in enhanced cytotoxic action of acylated derivatives of ascorbate to tumor cells. Biochim Biophys Acta 18: 144-151, 1988

7. Miwa $\mathrm{N}$ and Yamazaki H: Potentiated susceptibility of ascites tumor to acyl derivatives of ascorbate caused by balanced hydrophobicity in the molecule. Exp Cell Biol 54: 245-249, 1986.

8. Kageyama K, Onoyama Y, Kimura M, Yamazaki H and Miwa N: Enhanced inhibition of DNA synthesis and release of membrane phospholipids in tumour cells treated with a combination of acylated ascorbate and hyperthermia. Int J Hyperthermia 7: 85-91, 1991.

9. Pajonk F, Ophoven A and McBride WH: Hyperthermia-induced proteasome inhibition and loss of androgen receptor expression in human prostate cancer cells. Cancer Res 65: 4836-4843, 2005.

10. Harris M: Criteria of viability in heat-treated cells. Exp Cell Res 44: 658-661, 1966.

11. Palzer RJ and Heidelberger C: Studies on the quantitative biology of hyperthermic killing of HeLa cells. Cancer Res 33: 415-421, 1973 .

12. Gerner EW, Boone R, Connor WG, Hicks JA and Boone ML: A transient thermotolerant survival response produced by single thermal doses in HeLa cells. Cancer Res 36: 1035-1040, 1976.

13. Mondovì B, Finazzi Agrò A, Rotilio G, Strom R, Moricca G and Rossi Fanelli A: The biochemical mechanism of selective heat sensitivity of cancer cells. II. Studies on nucleic acids and protein synthesis. Eur J Cancer 5: 137-146, 1969.

14. Henle KJ and Leeper DB: Effects of hyperthermia (45 degrees) on macromolecular synthesis in Chinese hamster ovary cells. Cancer Res 39: 2665-2674, 1979.

15. Kageyama K, Onoyama Y, Nakanishi M and Ito K: New culture tube with an inside wall devised for studies of short-term hyperthermia. Int J Hyperthermia 4: 567-570, 1988.

16. Tanaka H, Kageyama K, Kusumoto K, Asada R and Miwa N: Antitumor and antiinvasive effects of diverse new macrocyclic lactones, alkylolides and alkenylolides, and their enhancement by hyperthermia. Oncol Rep 18: 1257-1262, 2007.

17. Asada R, Kageyama K, Tanaka H, Mimura H and Miwa N: The antitumor activities of the structurally-similar two-species aromatics Tonalide and Pearlide and the enhancement of their effects by hyperthermia. Mol Med Rep 2: 33-37, 2009.

18. Asada R, Kageyama K, Tanaka H, Matsui H, Kimura M, Saitoh Y and Miwa N: Antitumor effects of nano-bubble hydrogendissolved water are enhanced by coexistent platinum colloid and the combined hyperthermia with apoptosis-like cell death. Oncol Rep 24: 1463-1470, 2010.

19. Saito K, Oku T, Ata N, Miyasiro H and Saiki I: A modified and convenient method for assessing tumor cell invasion and migration and its application to screening for inhibitors. Biol Pharm Bull 20: 345-348, 1997.

20. Liu J W, Kayasuga A, Nagao N, Masatsuji-Kato E, Tuzuki T and Miwa N: Repressions of actin assembly and RhoA localization are involved in inhibition of tumor cell motility by lipophilic ascorbyl phosphate. Int J Oncol 23: 1561-1567, 2003.

\section{References}

1. Edgar JA: Dehydroascorbic acid and cell division. Nature 2273: 24-26, 1970.

2. Cameron E, Pauling L and Leibovitz B: Ascorbic acid and cancer: a review. Cancer Res 39: 663-681, 1779. 